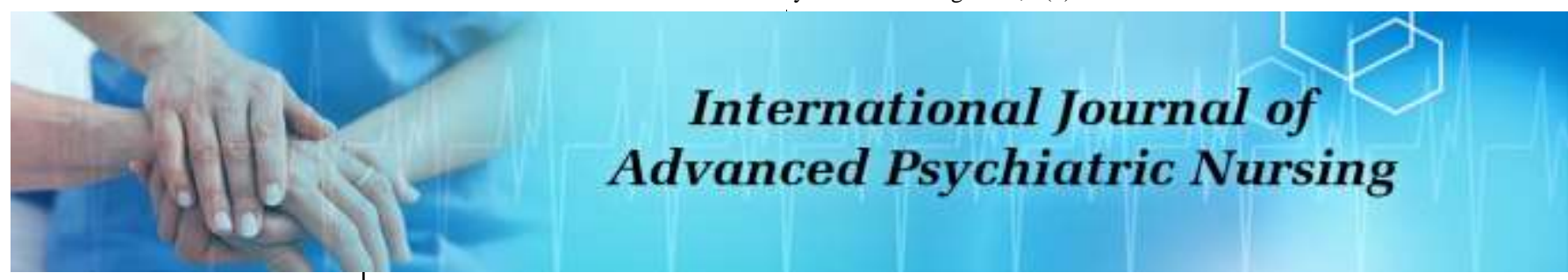

E-ISSN: 2664-1356 P-ISSN: 2664-1348 www.psychiatricjournal.net IJAPN 2021; 3(2): 01-04

Received: 02-04-2021

Accepted: 07-05-2021

Dr. Shakti Singh Soni Vice-Principal cum H.O.D. Mental Health (Psychiatric) Nursing, S.N. College of Nursing, Sri Ganganagar, Rajasthan, India
Corresponding Author: Dr. Shakti Singh Soni Vice-Principal cum H.O.D. Mental Health (Psychiatric) Nursing, S.N. College of Nursing, Sri Ganganagar, Rajasthan, India

\title{
A study to asses the occupational stress and job satisfaction of staff nurses working in selected Hospitals, Sri Ganganagar
}

\section{Dr. Shakti Singh Soni}

DOI: $\underline{\text { https://doi.org/10.33545/26641348.2021.v3.i2a.54 }}$

\begin{abstract}
Introduction: With the growing demand and progress in nursing, the pressure on nurses has also increased. It is often seen that nursing work is under great pressure. This is especially true for staff nurses who work in specialized areas.

Methods: A case-by-step modeling process was selected to select 100 nurses working in a psychiatric hospital. Data collected were analyzed using descriptive and interactive statistics. By looking at the nature of the problem and achieving research objectives the design of descriptive research was adopted. The completed closed questionnaire was designed to assess occupational stress and job satisfaction for psychiatric nurses.

Results: The distribution of nurses of their age showed that the highest percentage (58\%) of nurses was between the ages of 31-40, followed by staff between the ages of 41-50 and (32\%). Only (10\%) of employees were between the ages of 51-60.

In the event of changes without notice $32 \%$ sometimes and $24 \%$ remain annoyed. While taking disciplinary action with a simple error of $30 \%$ at one point, $28 \%$ always get upset. $36 \%$ sometimes and $24 \%$ usually feel disappointed when they don't get a good job.

Conclusion: Anxiety score is 128.5 and work satisfaction score was 67 . There was a significant correlation between job stress and job satisfaction for psychiatric nurses $(\mathrm{r}-0.625, P<0.01)$.

There was a significant relationship between job stress and age $(P<0.05)$ distance from workplace and year of experience $(P<0.05)$. Job satisfaction had a significant relationship with the number of children $(P<0.05)$ and monthly income $(P<0.05)$, some of which varied in population was not correlated.
\end{abstract}

Keywords: Occupational stress, job satisfaction, psychiatric nurses, hospital

\section{Introduction}

Nursing or patient care has existed since the dawn of civilization. But it did not receive much recognition until the beginning of the 19th century. It originated as a profession in the late 19 th century and by the 20th century it had developed into a special one with a specific function ${ }^{[1]}$.

It is often seen that nursing work is under great pressure. This is especially true for staff nurses who work in specialized areas. This causes stress, affects the performance of nurses and ultimately affects patient care ${ }^{[2]}$.

Stress is defined as a recurrence of an event associated with signs of increased arousal and motivational evidence associated with trauma, this affects the performance of the task ${ }^{[3]}$.

If you like your job intensely, you will experience high job satisfaction.Job satisfaction is an individual emotional reaction to the jobitself ${ }^{[4]}$.

Shifts in the health-care sector, particularly in psychiatric nursing practise, have a profound impact on nursing as a health-care specialty and a major component of the health-care delivery system ${ }^{[5]}$.

\section{Methodology}

Research design: Descriptive study is designed to get more information about features in a particular field of study.

Setting: The current study was conducted in selected hospitals in Sri ganganagar.

Sample: People consist of psychiatric nurses working in selected hospitals in Sri ganganagar. 
Sample Size: The 100 nurses working in the psychiatric departments were selected based on the availability of the sample at the time of data collection.

Sample techniques: Making examples of the simplest random is the basis of possible measurement strategies.

\section{Description of the tool}

The questionnaire had 3 parts:-

Tool I: Demographic Performa

Tool II: Stress assessment rating scale

Tool III: Job satisfaction scale

\section{Results}

Part I: Description of demographic variables of the nurses

- Distribution of the staff nurses according to their age showed that highest percentage $(58 \%)$ of the nurse were between the age group of 31-40 years, followedby the staff between age group of $41-50$ is $(32 \%)$. Only (10\%) of the staff was between the age group of 51-60 years.

- Percentage distribution of the samples according to sex revealed that majority $(80 \%)$ of the staff nurses were female and only (20\%) of the samples were male.

- Percentage distributions of the nurses regarding marital status revealed that highest $(70 \%)$ of the respondents were married. (22\%) of the respondents were single, $(6 \%)$ of them were widow and the lowest i.e. only $(2 \%)$ of the nurses were separated from theirspouse.

- Percentage distribution of samples according to type of residence revealed that highest percentages $(54 \%)$ of the respondents were having their own house and $46 \%$ of the respondents were staying in a rented house. None of the nurses were staying either as paying guests or in the hospital quarters.

- Percentage distribution of the sample according to their type of family showed that the highest percentage (74\%) of the staff nurses belong to the nuclear family, rest $(26 \%)$ of the staff nurses belong to joint family. The distribution also showed that none of the respondents belong to extended type of family.

- Distribution of samples in terms of Professional qualification indicated that a majority $(90 \%)$ of nurses had completed their GNM course. Only (8\%) of the nurses had undergone Diploma in Psychiatric Nursing and $(2 \%)$ of them had undergone graduation training. None of the respondents had any other professional qualification.

- Percentage distribution of samples according to number of children showed that the highest percentage $(36 \%)$ of the staff nurses did not have any children followed by $(30 \%)$ of the staff nurses had only one child, $(22 \%)$ of them had 2 children and least percentage $(12 \%)$ of them had 3 or more children.

- Percentage distribution of samples with reference to their year of experience revealed that highest percentage $(40 \%)$ of the staff were having more than 15 years of experience followed by $(28 \%)$ staff having below 5 years, $(22 \%)$ of the staff having 6-10years of experience and only (10\%) of the staff were having experience between 11-15 years.

- Percentage distribution of the staff nurses according to their income per month described that highest percentage $(50 \%)$ of the staff were coming under the group of Rs. 6,000-8,000 per month followed by $(22 \%)$ of them coming under group of Rs. 12,000-14,000. (16\%) were coming between Rs. 9,000-11,000 and the least percentage (12\%) was earning Rs. 15,000 andabove.

- The percentage distribution of the respondents according to their distance of work place to their home showed that highest $(74 \%)$ of the staff were staying within $6 \mathrm{kms}$ from their work place and (18\%) were staying more than $6 \mathrm{kms}$ away from their work place. Only $(8 \%)$ of the staff were staying within thecampus.

- The percentage distribution of the samples with reference to their mode of transport revealed that the highest percentage $(72 \%)$ of the staff were coming by city bus and the rest $28 \%$ of the staff nurses were coming by their own vehicle.

Part II: The analysis of the level of stress and job satisfaction of nurses working in psychiatric hospital

- The distribution of staff nurses according to their stress in relation to work environment revealed that highest percentage $(74 \%)$ of the staff nurses were having mild stress followed by $18 \%$ of the staff nurses had moderate level and $8 \%$ of the staff were experiencing nil stress level. None of the respondents were having severe kind of stress regarding work place environment.

- The percentage distribution of the samples regarding the level of stress in relation to the work schedule indicated that the highest percentage $(55 \%)$ of the staff nurses was experiencing moderate level of stress. $25 \%$ percentages of staff nurses were experiencing severe level of stress and $20 \%$ of staff experiencing mild stress whereas only two percent of nurses were experiencing nil stress level.

- Assessment of the level of stress of staff nurses in relation to workload revealed that highest percentage $(72 \%)$ of the respondents experienced moderate stress and $26 \%$ of the sample experienced mild level of stress, $2 \%$ of the staff experience severe stress and non of the staff experience nil stresslevel.

- Distribution of the respondents according to their level of stress in relation to emergency duty revealed that the highest percentage $(44 \%)$ of the staff nurses experienced moderate level of stress during emergency situation followed by $30 \%$ of the staff nurses experienced severe stress, $18 \%$ of the staff experienced mild stress and the lowest percentage $(8 \%)$ of staff experienced nil stresslevel.

- Sample distribution revealed that $55 \%$ of the nurses who were working in the psychiatric hospital were experiencing severe stress, 35\% of the staff nurses experienced moderate stress and $10 \%$ of the staff experienced mild level of stress. Regarding the distance from the work place only four percent of the respondents were experiencing nil stress level.

- Analysis revealed that highest percentage $(65 \%)$ of the staff nurses were experiencing moderate level of stress followed by $20 \%$ of the staff were experiencing mild stress, $15 \%$ of the staff nurses were experiencing severe stress. But only 4\%staff was there who were experiencing nil stress level regarding the family problems. 
- Assessment of the level of stress in staff nurses regarding supervision in work place stated that highest percentage $(45 \%)$ of the staff nurses experienced moderate stress. $36 \%$ of the staff had mild stress, $13 \%$ was having nil stress. Only $6 \%$ of the staff showed severestress.

- The study revealed that highest percentage (36\%) of the staff nurses were having severe stress related to promotional benefits while $34 \%$ were having moderate stress, $26 \%$ were having mild stress. Only $4 \%$ of the staff nurses were having nil level of stress regarding promotional benefits provided to them.

Section B: Assessment of overall stress among the staff nurses working in psychiatric hospital

The total number of questions in stress assessment scale was 57. The highest score was 228 and lowest is 0 . The total score was divided into four sections like nil (0-56), mild (57-113), moderate (114-117), severe (171-228).

Distribution of samples according to level of stress experienced by staff nurses

Assessment of overall level of stress experienced by the staff nurses revealed that the highest percentage $(76 \%)$ of the staff nurses experience moderate level of stress, $20 \%$ of the staff nurses experience mild level of stress. $4 \%$ of the staff nurses experienced severe stress and nil stress in their work place.

Section C: Assessment of job satisfaction among staff nurses working in psychiatric hospitals

Total number of questions in job satisfaction scale was thirty-eight. The score in the scale ranged between $0-152$. Total score was divided into four sections namely strongly satisfied (0-37), satisfied (38-75), dissatisfied (76-113), strongly dissatisfied (114-152).

Distribution of samples according to level of job satisfaction of staff nurses working in psychiatric hospital

Analysis revealed that highest percentage (76\%) of the staff nurses were satisfied with their job situation followed by $20 \%$ were dissatisfied and $4 \%$ were strongly satisfied in their job. The study also showed that none of the staff nurses were strongly dissatisfied in their job.

\section{Section D: Item-wise analysis of the stress score}

Item-wise analysis of stress scores in relation to work environment

It was observed that staff nurses were having stress sometimes regarding work environment except night security, where more than $60 \%$ said that it was always stressful due to in adequate security during night hours.

Item-wise analysis of stress scores in relation to work schedule

It is observed that more than $70 \%$ of the staff always experience stress due to night duty hours where as in other areas they sometimes experience stress in relation to work schedule.

Item-wise analysis of stress scores in relation to workload

Staff who faced difficulty sometimes and always works with in adequately trained staff was $50 \%$ and $20 \%$ respectively.
Sixty percentages of the staff felt inconvenient when doctors took rounds at their own time.

Item-wise analysis of stress in staff nurses in relation to emergency

It is being observed that most of the staff always or frequently felt difficulty in handling suicidal and stupors patients.

Item-wise analysis of stress in psychiatric nurses in relation to distance from workplace

It is observed that most of the persons were having stress either frequently or always due to the distance from the workplace.

Item-wise analysis of stress score in psychiatric nurses in relation to family problems

Analysis showed that $32 \%$ always $26 \%$ sometimes and $18 \%$ frequently became tensed due to the sickness of family members. In case of giving attention to the family $48 \%$ sometimes $32 \%$ frequently and $16 \%$ always felt guilty. Thirty-six percentages sometimes, $28 \%$ always and $26 \%$ frequently stated that they were disturbed when children were sick at home. In case of spending time with spouse $36 \%$ sometimes, $22 \%$ frequently felt unhappy. In relation to financial crisis $50 \%$ always, $44 \%$ sometimes became frustrated. Forty-eight percentages occasionally and $26 \%$ never felt any difficulty to adjust with their in-laws.

Item-wise analysis of stress score in staff nurses in relation to supervision

In case of changes without notification $32 \%$ sometimes and $24 \%$ always became upset. While taking disciplinary action for a simple mistake $30 \%$ sometimes, $28 \%$ always became upset. $36 \%$ sometimes and $24 \%$ frequently felt let down when they did not get appreciation for a good work.

Item-wise analysis of stress score in psychiatric nurses in relation to promotional and other benefits

It is observed that most of the staff nurses were frustrated due to not getting chance for higher study and promotion after proper qualifications.

Part III - Relationship between level of stress and job satisfaction of staff nurses working in psychiatric hospital

Section A: Correlation between stress and job satisfaction

The Karl Pearson's Correlation Coefficient between stress and job satisfaction score was 0.625 ( $P<0.01$ level, highly significant).

Section B: Association between occupational stress of psychiatric nurses and selected demographic variables There is no association between stress of the nurses working in selected hospital and demographic variables.

Association between occupational stress and selected demographic variables of psychiatric nurses

There was a significant association in occupational stress of staff nurses working in psychiatric hospital and the demographic variables such as age, year of experience and distance of residence from the work place. 
Section C: Association between job satisfaction of psychiatric nurses and selected demographic variables

There is no significance relationship in the job satisfaction of psychiatric nurse and selected demographic variables.

\section{Conclusion}

The findings in relation to item-wise analysis showed $60 \%$ accepts night security was inadequate $62 \%$ indicated noise created by the patients were troublesome. The study also indicated that $66 \%$ staff nurses were irritated for being dependent on others for help, $50 \%$ faced difficulty in managing wards with less staff, $72 \%$ were tired due to long night shift hours. Difficulty in working with noncooperative staff $(50 \%)$, guilty for giving attention to family (80\%), inability to cope with financial crisis $(50 \%)$, strict supervisors (56\%), inadequate chance for attending workshop and conferences (84\%), improper promotional benefits $(60 \%)$, not getting leave at the time of need $(72 \%)$ too enhance the stress level in psychiatric nurses.

\section{Summary}

The pressure count is 128.5 and it means 67 satisfaction points have been obtained. By calculating the correlation between Karl Pearson's relationship ( $\mathrm{r}=0.625, P<0.01)$ it was found that there was a significant association between job stress and occupational satisfaction for nurses working in a psychiatric hospital, indicating positive relationships.

There was a significant association in occupational stress and age (df-2, $P<0.05$ level) distance from work place (df-1, $P<0.05$ ) and year of experience (df-1, $P<0.05$ ). Job satisfaction also had significant association with number of children (df-2, $P<0.05)$ and income per month (df-1, $P<0.05)$. Other demographic variables like sex, marital status, residence, professional qualification, type of family, type of transport did not have any significant association.

\section{References}

1. Stuart GW, Laria MT. Principles and Practice of Psychiatric Nursing, $7^{\text {th }}$ Edition, New Delhi; Mossby Harcoart (India) Pvt. Ltd., 2001.

2. Supe Avinash. Managing stress in Nursing professionals, The Nursing Journal of India 2000;LXXXXI(10):221-224.

3. Cottrell S. Occupational stress and Job satisfaction in Mental health Nursing; focused interventions through evidence based assessment. Journal of Psychiatric Mental Health Nursing 2001;52(2):232-4. Available from http://www.google.co.in 13/10/04.

4. Joseph Jeny. Job satisfaction of laboratory technician in a selected hospital in Mangalore, unpublished project report, M. Sc. hospital management student, submitted to Mangalore University 1992.

5. Peter HE, Macfarlane AV, O'Brien-Pallas L. Analysis of the moral habitability of the nursing work environment. Journal of Advanced Nursing 2004;47(4):356-367. 